\title{
Dispersion Granulation Method Leveraging pH Responsiveness of Monoalkyl Sulfosuccinate
}

\author{
Naoya Hashimoto ${ }^{1}$, Koji Kawaguchi ${ }^{1 *}$ and Kotaro Yoshioka ${ }^{2}$ \\ ${ }^{1}$ Surfactants Research Department, Sanyo Chemical Industries, Ltd., (11-1 lkkyo Nomoto-cho, Higashiyama-ku, Kyoto 605-0995, JAPAN) \\ ${ }^{2}$ PEB Research Department, Sanyo Chemical Industries, Ltd., (11-1 Ikkyo Nomoto-cho, Higashiyama-ku, Kyoto 605-0995, JAPAN)
}

\begin{abstract}
Monoalkyl sulfosuccinate is an anionic surfactant having two types of hydrophilic groups in one molecule, carboxylic acid group and sulfonic acid group, resulting in three ionization states depending on its pH. In state I, both carboxylic acid and sulfonic acid groups are not ionized; in state II, only sulfonic acid group is ionized; and in state III, both carboxylic acid and sulfonic acid groups are ionized. The ionization state affects the hydrophile-lipophile balance (HLB) of the surfactant, an index of the distribution coefficient of water/oil ratio of the surfactant. The decrease in HLB promotes the adsorption of the surfactant to the oil/water interface and improves the interface activity. State II has high emulsifying property for high interface activity but low water solubility. In contrast, state III has low emulsifying property for low interface activity but high water solubility. We applied the $\mathrm{pH}$ responsiveness of monoalkyl sulfosuccinate to the dispersion granulation method to change the state from II to III in a mild range of pH (weak acidity and weak alkalinity). Consequently, we successfully developed a novel dispersion granulation method that decreased the amount of surfactant needed for emulsifying resin solution by employing state II for its high emulsifying property, and we also reduced the amount of surfactant remaining on resin particles after the washing process by employing state III for its high water solubility.
\end{abstract}

Key words: monoalkyl sulfosuccinate, $\mathrm{pH}$ responsiveness, ionization state, dispersion granulation method

\section{INTRODUCTION}

Anionic surfactants such as sodium laurate and sodium lauryl benzene sulfonate have a hydrophilic group that becomes anionic upon ionizing when dissolved in water ${ }^{1,2)}$. Owing to this hydrophilic group, which is an acid group with pKa such as a carboxylic acid group or sulfonic acid group, the ionization equilibrium is greatly affected by the $\mathrm{pH}$ of the water solution ${ }^{3)}$. When the $\mathrm{pH}$ of the surfactant water solution is less than pKa of the hydrophilic group, the ionization equilibrium moves to a nonionization state; similarly, the equilibrium moves to an ionization state when the $\mathrm{pH}$ of the surfactant water solution is more than $\mathrm{pKa}$ of the hydrophilic group. The extent to which the equilibrium moves between the nonionization and the ionization state significantly influences the hydrophile-lipophile balance (HLB); HLB is an index of the distribution coefficient of the water/oil ratio of the surfactant, which indicates the $\mathrm{pH}$ responsiveness of anionic surfactants ${ }^{4)}$.

However, because anionic surfactants generally have only one type of hydrophilic group in one molecule, they show only two states-ionization state or nonionization state triggered by $\mathrm{pH}$. When the hydrophilic group of the surfactant enters the nonionization state, the surfactant becomes insoluble in water owing to a decrease in the $\mathrm{HLB}^{5)}$. In addition, the nonionization state causes particles that are stabilized in the suspension by anionic surfactants to aggregate owing to the weakening electrostatic repulsion ${ }^{6,7)}$. Thus, the pH responsiveness of general anionic surfactants is not practical.

In this light, we have developed a monoalkyl sulfosuccinate having two types of hydrophilic groups: sulfonic acid group and carboxylic acid group. By varying the $\mathrm{pKa}$ in one molecule, the surfactant showed practical $\mathrm{pH}$ responsiveness. We considered that monoalkyl sulfosuccinate could change the ionization state of the carboxylic acid group and HLB in a mild pH range between weak acidity and weak alkalinity, maintaining the dispersion stabilization effect of the emulsion and solubility of the surfactant in water by employing the ionization state of the sulfonic acid.

This type of surfactant has long been used as an ingredient in shampoo and body soap for the characteristic of low

\footnotetext{
*Correspondence to: Koji Kawaguchi, Surfactants Research Department, Sanyo Chemical Industries, Ltd., 11-1 Ikkyo Nomoto-cho, Higashiyama-ku, Kyoto 605-0995, JAPAN

E-mail: k.kawaguchi@sanyo-chemical.com

Accepted October 10, 2014 (received for review June 1, 2014)

Journal of Oleo Science ISSN 1345-8957 print / ISSN 1347-3352 online

http://www.jstage.jst.go.jp/browse/jos/ http://mc.manusriptcentral.com/jjocs
} 
skin irritation, high washing performance, and high foaming property ${ }^{8)}$. Sanyo Chemical Industries, Ltd., has been selling such surfactants with brand names such as "BEAU-

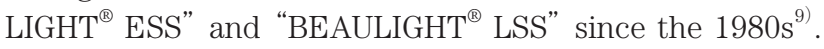
However, they have not been used from the viewpoint of $\mathrm{pH}$ responsiveness. We investigated the possibility of applying the $\mathrm{pH}$ responsiveness of the surfactant to the dispersion granulation method to provide a resin particle.

Resin particles are produced by two methods ${ }^{10)}$. One is the polymerizing granulation method, in which resin particles are formed by polymerizing a monomer by processes such as emulsification polymerization and suspension polymerization, and the other is the dispersion granulation method, in which resin particles are formed by emulsifying a resin solution with surfactants. Only polymerizable monomers such as styrene can be used in the polymerizing granulation method, and only polycondensation resins such as polyester can be used in the dispersion granulation method. However, the dispersion granulation method requires a considerable amount of surfactants to emulsify not only the resins but also the solvents necessary for dissolving the resin ${ }^{11-13)}$. In addition, a lot of water is required to wash off the surfactants remaining on the resin particles. Therefore, this method produces large amounts of wastewater containing a high density of surfactants, and the surfactants remaining on the resin particles undermine the performance of the resin particles.

We considered that applying the $\mathrm{pH}$ responsiveness of the monoalkyl sulfosuccinate to the dispersion granulation method was one of the best solutions to resolve the aforementioned issue.

\section{EXPERIMENTAL PROCEDURES}

\subsection{Materials}

We used three types of anionic surfactants with different hydrophilic groups: disodium polyoxyethylene alkyl sulfosuccinate (BEAULIGHT ${ }^{\circledR}$ ESS, Sanyo Chemical Industries (SCI), Ltd.), sodium polyoxyethylene lauryl ether sulfate (BEAULIGHT ${ }^{\circledR}$ NA-25S, SCI), and sodium polyoxyethylene lauryl ether acetate(BEAULIGHT ${ }^{\circledast}$ LCA $\left.-25 \mathrm{~N}, \mathrm{SCI}\right)$. Table 1 shows their chemical structures. We used sodium hydroxide aqueous solution and hydrochloric acid aqueous solution as $\mathrm{pH}$ adjusters. We prepared polyester resin A, which comprised polyoxyethylene (2 mol) bisphenol A/terephthalic acid $($ mol ratio $=58 / 42, \mathrm{Mn}=3,000)$, and polyester resin $\mathrm{B}$, which was a reactant of polyester resin $\mathrm{A}$ and 3-isocyanatomethyl-3,5,5-trimethylcyclohexyl isocyanate (IPDI) (polyester resin A/IPDI $=97 / 3$ (weight ratio), $\mathrm{Mn}=$ $80,000$, free NCO content $=1.0 \%)$. We dissolved polyester resin $\mathrm{A}$ and $\mathrm{B}($ weight ratio $=80 / 20)$ in ethyl acetate to prepare $30 \%$ resin solution. We prepared $25 \%$ epoxy resin emulsion by emulsifying bisphenol A diglycidyl ether (EPIKOTE $^{\circledR}$ 828, Momentive Performance Materials Inc.) in water with polyoxyethylene sorbitan monooleate $\left(\right.$ IONET $^{\circledR}$ T-80V, SCI), followed by extension reaction with ethylenediamine (EPIKOTE 828/ethylenediamine/IONET T-80V/ water $=23 / 2 / 5 / 70$ (weight ratio $)$. The volume average particle size (Dv) was $500 \mathrm{~nm}$. It is known that a resin emulsion as an emulsification auxiliary agent provides an emulsion or a suspension that has a sharp particle size distribution and high dispersion stabilization by hetero-aggregation ${ }^{14-16)}$.

\subsection{Calculating HLB of anionic surfactants}

We calculated the HLB of the anionic surfactant by the Oda method, which used the proportion of organicity to inorganicity of each component ${ }^{17)}$.

\subsection{Measurement of interface tension between anionic surfactants solution and liquid paraffin}

We measured the interface tension between the liquid paraffin and $1 \%$ surfactant water-solution $(\mathrm{pH}$ of the solution is adjusted accordingly) at $25^{\circ} \mathrm{C}$ by the pendant drop method using an automatic interface tension meter (Model PD-W, Kyowa Interface Science) .

\subsection{Synthesis of resin particles from polyester solution by dispersion granulation method}

We prepared a water solution of emulsifier that contained each concentration of anionic surfactants and $0.5 \%$ epoxy resin emulsion. We mixed the $30 \%$ polyester resin

Table 1 Chemical structure of anionic surfactants.

\begin{tabular}{|c|c|c|c|}
\hline $\begin{array}{c}\text { Anionic } \\
\text { surfactant }\end{array}$ & $\begin{array}{l}\text { Disodium polyoxyethylene } \\
\text { alkyl sulfosuccinate } \\
\text { "BEAULIGHT ESS" }\end{array}$ & $\begin{array}{l}\text { Sodium polyoxyethylene } \\
\text { lauryl ether sulfate } \\
\text { "BEAULIGHT NA-25S" }\end{array}$ & $\begin{array}{l}\text { Sodium polyoxyethylene } \\
\text { lauryl ether acetate } \\
\text { “BEAULIGHT LCA-25N” }\end{array}$ \\
\hline $\begin{array}{l}\text { Chemical } \\
\text { structure }\end{array}$ & $\begin{array}{c}\mathrm{RO}\left[\mathrm{CH}_{2} \mathrm{CH}_{2} \mathrm{O}\right]_{\mathrm{n}} \mathrm{CO}-\underset{\mathrm{CH}}{\mathrm{C}}-\mathrm{SO}_{3} \mathrm{Na} \\
\mathrm{CH}_{2} \mathrm{COONa} \\
\mathrm{R}=\mathrm{C}_{12} \mathrm{H}_{25} \sim \mathrm{C}_{14} \mathrm{H}_{29}, \mathrm{n}=\mathbf{2}\end{array}$ & $\begin{array}{c}\mathrm{RO}\left[\mathrm{CH}_{2} \mathrm{CH}_{2} \mathrm{O}\right]_{\mathrm{n}} \mathrm{SO}_{3} \mathrm{Na} \\
\mathrm{R}=\mathrm{C}_{12} \mathrm{H}_{25}, \mathrm{n}=\mathbf{2 . 5}\end{array}$ & $\begin{array}{c}\mathrm{RO}\left[\mathrm{CH}_{2} \mathrm{CH}_{2} \mathrm{O}\right]_{\mathrm{n}} \mathrm{CH}_{2} \mathrm{COONa} \\
\mathbf{R}=\mathrm{C}_{12} \mathrm{H}_{25}, \mathrm{n}=\mathbf{3}\end{array}$ \\
\hline
\end{tabular}


solution with the water solution of emulsifier at the weight ratio of 40:60 and emulsified the mixture using an ultrahigh-speed mixing system (ROBOMICS, Tokusyu Kika Kogyo) at 12, $000 \mathrm{rpm}$ for $2 \mathrm{~min}$. Then, we stirred the solution using a jar tester(MSJ-6N, Miyamoto Corporation) at $200 \mathrm{rpm}$ for $1 \mathrm{~h}$ and obtained a polyester resin particle dispersion after removing ethyl acetate at $30^{\circ} \mathrm{C}$ by an evaporator for $2 \mathrm{~h}$. We centrifuged the dispersion at 3, $000 \mathrm{rpm}$ for $5 \mathrm{~min}$. We discarded the supernatant and retained the precipitate of the resin particles. To remove the remaining surfactants from the resin particles, we implemented a washing process in which we added two times the amount of alkali water ( $\mathrm{pH}$ 8) to the precipitate, stirred it using an ultrahigh-speed mixing system at 2,000 rpm for $2 \mathrm{~min}$, and removed the supernatant after centrifuging the dispersion at 3,000 $\mathrm{rpm}$ for $5 \mathrm{~min}$. We repeated the washing process several times and obtained the resin particles after drying the precipitate at $30^{\circ} \mathrm{C}$.

We measured the volume average particle size (Dv) and number average particle size(Dn) of the resin particles using a MultisizerTM 3 (Coulter Counter ${ }^{\circledR}$, Beckman Coulter).

\subsection{Measurement of surfactants in resin particle by LC- MS}

Methanol was added to the resin particles to dissolve the surfactant remaining on the particles. The supernatant was filtered through a PTFE filter (Syringe Filter (pore size: 0.2 $\mu \mathrm{m})$, Whatman). The quantity of surfactant remaining on the particles was estimated by measuring the quantity of the surfactant in the filtrate using LC-MS (LCMS-8030, Shimadzu).

\section{RESULTS AND DISCUSSION}

3.1 Behavior of interface tension between anionic surfactants solution and liquid paraffin by $\mathrm{pH}$

Figure 1 shows that the behavior of the interface tension between $1 \%$ anionic surfactants solution and liquid paraffin was intergraded along with the $\mathrm{pH}$ of the solution. We

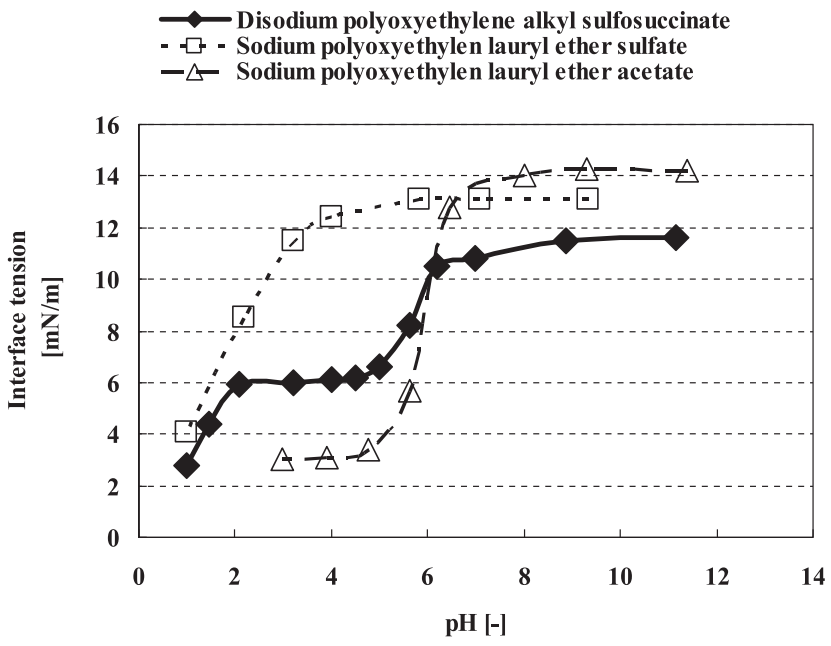

Fig. 1 Behavior of interface tension of anionic surfactants by $\mathrm{pH}$.

considered that the inflection point of the $\mathrm{pH}$ corresponded to pKa of the hydrophilic group. In light of the relationship between pKa and pH based on formula (1), the amount of nonionized acid was equal to that of ionized acid at the point where $\mathrm{pH}$ was equal to $\mathrm{pKa}$. Therefore, the HLB of anionic surfactants dramatically changed at $\mathrm{pH}$ equivalent to $\mathrm{pKa}$ of the hydrophilic group. Because HLB is an index of the distribution coefficient of water/oil, the HLB affects the interface activity, implying that HLB influences the stepwise change of the interface tension along with the $\mathrm{pH}$ of the solution.

$$
\mathrm{pH}=\mathrm{pKa}+\log \left[\mathrm{A}^{-}\right] /[\mathrm{AH}]
$$

The interface tensions of sodium polyoxyethylene lauryl ether sulfate and sodium polyoxyethylene lauryl ether acetate changed in one step because they had only one hydrophilic group providing two types of ionization states in which the hydrophilic group was ionized or nonionized at the border of equivalent $\mathrm{pH}$ to pKa. Table 2 shows the ionization state of sodium polyoxyethylene lauryl ether acetate at each pH. Sodium polyoxyethylene lauryl ether acetate had an inflection point at $\mathrm{pH} 6$ because of the $\mathrm{pKa}$

Table 2 Ionization states of sodium polyoxyethylene lauryl ether acetate.

\begin{tabular}{|c|c|c|}
\hline Ionization state & I (Non-ionization state) & II (Ionization state) \\
\hline Chemical structure & $\mathrm{RO}\left[\mathrm{CH}_{2} \mathrm{CH}_{2} \mathrm{O}\right]_{n} \mathrm{CH}_{2} \mathrm{COOH}$ & $\mathrm{RO}\left[\mathrm{CH}_{2} \mathrm{CH}_{2} \mathrm{O}\right]_{n} \mathrm{CH}_{2} \mathrm{COO}^{-}$ \\
\hline pH & $\begin{array}{c}4 \\
\text { (less than pKa of carboxylic acid) }\end{array}$ & $\begin{array}{c}8 \\
\text { (more than pKa of carboxylic acid) }\end{array}$ \\
\hline HLB & 9.9 & 16.1 \\
\hline Interface tension & $3.1 \mathrm{mN} / \mathrm{m}$ & $14.0 \mathrm{mN} / \mathrm{m}$ \\
\hline
\end{tabular}


Table 3 Ionization states of disodium polyoxyethylene alkyl sulfosuccinate.

\begin{tabular}{|c|c|c|c|}
\hline $\begin{array}{l}\text { Ionization } \\
\text { state }\end{array}$ & I (Non-ionization state) & II (Ionization state -1) & III (Ionization state -2) \\
\hline $\begin{array}{l}\text { Chemical } \\
\text { structure }\end{array}$ & $\begin{array}{r}\mathrm{RO}\left[\mathrm{CH}_{2} \mathrm{CH}_{2} \mathrm{O}\right]_{\mathrm{n}} \mathrm{CO}-\mathrm{CH}-\mathrm{SO}_{3} \mathrm{H} \\
\mathrm{CH}_{2} \mathrm{COOH}\end{array}$ & $\underset{\mathrm{RO}_{2}\left[\mathrm{CH}_{2} \mathrm{CH}_{2} \mathrm{O}\right]_{\mathrm{n}} \mathrm{CO}-\mathrm{CH}_{\mathrm{C}}-\mathrm{SO}_{3}{ }^{-}}{\mathrm{CH}_{2} \mathrm{COOH}}$ & $\begin{array}{r}\mathrm{RO}_{\left[\mathrm{CH}_{2} \mathrm{CH}_{2} \mathrm{O}\right]_{\mathrm{n}} \mathrm{CO}-\mathrm{CH}_{-}-\mathrm{SO}_{3}^{-}}^{{ }^{-}} \\
\mathrm{CH}_{2} \mathrm{COO}^{-}\end{array}$ \\
\hline pH & $\begin{array}{c}1 \\
\text { (less than pKa of sulfonic acid) }\end{array}$ & $\begin{array}{c}4 \\
\text { (between pKa of carboxylic acid } \\
\text { and sulfonic acid) }\end{array}$ & $\begin{array}{c}8 \\
\text { (more than pKa of carboxylic acid) }\end{array}$ \\
\hline HLB & 15.3 & 21.5 & 27.8 \\
\hline $\begin{array}{c}\text { Interface } \\
\text { tension }\end{array}$ & $2.8 \mathrm{mN} / \mathrm{m}$ & $6.1 \mathrm{mN} / \mathrm{m}$ & $11.5 \mathrm{mN} / \mathrm{m}$ \\
\hline
\end{tabular}

of carboxylate. By adjusting the $\mathrm{pH}$ from 8 to 4 , the carboxylate changed to the nonionized state and the interface tension declined from 14.0 to $3.1 \mathrm{mN} / \mathrm{m}$. The maximum concentration of inorganic salt produced by $\mathrm{pH}$ adjustment was $\sim 1,500 \mathrm{ppm}$ in the solution. We confirmed that adding the same concentration of inorganic salt to $1 \%$ surfactant solution resulted in the interface tension decreasing by only $1.2 \mathrm{mN} / \mathrm{m}$, and we concluded that $\mathrm{pH}$ strongly affected the interface tension compared to the inorganic salt. The interface tension of disodium polyoxyethylene alkyl sulfosuccinate changed in two steps because disodium polyoxyethylene alkyl sulfosuccinate had carboxyl and sulfonyl groups providing three types of ionization states, where hydrophilic groups were ionized and/or nonionized as shown in Table 3.

\subsection{Relation between $\mathrm{pH}$ of surfactants under emulsifi- cation and amount of surfactants required to obtain resin particles}

Figure 2 shows the relationship between the amount of surfactant necessary for obtaining polyester resin particles (Dv: $5.0 \pm 1.0, \mathrm{Dv} / \mathrm{Dn}:<1.20$ ) and the $\mathrm{pH}$ of the solution in the emulsification. When we used sodium polyoxyethylene lauryl ether sulfate, the $\mathrm{pH}$ of which was below three, we could not emulsify the resin solution and obtain the desired particles despite the fact that the interface tension was low, as shown in Fig. 1. The lack of electrostatic repulsion caused recondensation of miniaturized particles because the $\mathrm{pH}$ of the solution was below $\mathrm{pKa}$ of the hydrophilic group. In granulation by emulsification, miniaturization and recondensation of particles occurred simultaneously. In this situation, the interface tension would be a factor of miniaturization under emulsification, and the electrostatic repulsion would be a factor of recondensation of miniaturized particles. In the emulsification using anionic surfactants, it is necessary to consider the electrostatic repulsion between particles.

On the other hand, when the $\mathrm{pH}$ was above three or more in which the distributed stabilization effected by

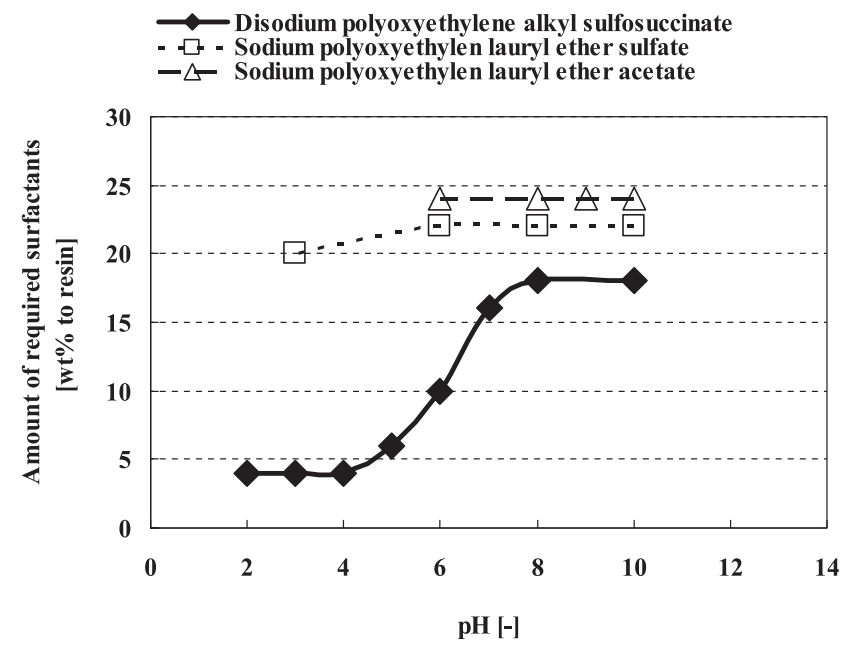

Fig. 2 Amount of surfactant required to get the resin particle.

electrostatic repulsion was high, the necessary amount of surfactants was more than $20 \mathrm{wt} \%$ to resins because of the high interface tension. Similarly, when we used sodium polyoxyethylene lauryl ether acetate, we could not emulsify the resin solution at less than $\mathrm{pH} 6$, and we needed more than $20 \mathrm{wt} \%$ of the surfactant to resins at more than $\mathrm{pH} 6$. $20 \mathrm{wt} \%$ to resins corresponded to $4 \%$ surfactants in the emulsifier solution, according to chapter 2.4. In the case of sodium polyoxyethylene lauryl ether acetate, the interface tension of the $4 \%$ solution was $13.2 \mathrm{mN} / \mathrm{m}$, which is 0.8 $\mathrm{mN} / \mathrm{m}$ lower than that of the $1 \%$ solution. We confirmed that the concentration of surfactants did not strongly affect the interface tension.

By contrast, disodium polyoxyethylene alkyl sulfosuccinate at $\mathrm{pH} 4$, where the carboxylic acid group was nonionized and sulfonic acid group was ionized, had low interface tension and high electrostatic repulsion. Therefore, the amount of surfactants required for emulsification was reduced to $\sim 4 \mathrm{wt} \%$ to resins, which was almost one-fifth the amount of surfactants used in other examples. Reduc- 
Table 4 Amount of remaining surfactant after washing twice.

\begin{tabular}{|c|c|c|c|}
\hline $\begin{array}{c}\text { Anionic } \\
\text { surfactant }\end{array}$ & $\begin{array}{c}\text { Disodium polyoxyethylene } \\
\text { alkyl sulfosuccinate }\end{array}$ & $\begin{array}{c}\text { Sodium polyoxyethylene } \\
\text { lauryl ether sulfate }\end{array}$ & $\begin{array}{c}\text { Sodium polyoxyethylene } \\
\text { lauryl ether acetate }\end{array}$ \\
\hline $\begin{array}{c}\text { pH under } \\
\text { emulsification }\end{array}$ & "BEAULIGHT ESS" & "BEAULIGHT NA-25S" & "BEAULIGHT LCA-25N" \\
\hline $\begin{array}{c}\text { Amount of } \\
\text { required } \\
\text { surfactants }\end{array}$ & 4 & 8 & 24 wt\% to resin \\
\hline $\begin{array}{c}\text { HLB } \\
\text { at pH8 }\end{array}$ & $4 \mathrm{wt} \%$ to resin & $22 \mathrm{wt} \%$ to resin & \\
\hline $\begin{array}{c}\text { Amount of } \\
\text { remaining } \\
\text { surfactants } \\
\text { after washing } \\
\text { twice }\end{array}$ & 27.8 & 20.2 & 16.1 \\
\hline
\end{tabular}

ing the amount of surfactants could reduce the cost of raw materials as well as the cost of wastewater treatment from washing process.

\subsection{Amount of surfactant remaining on resin particles}

We investigated the effect of the washing process by weak alkali water $(\mathrm{pH} 8)$ on the amount of surfactant remaining on the resin particles obtained by emulsification at $\mathrm{pH} 8$ with sodium polyoxyethylene lauryl ether sulfate, $\mathrm{pH}$ 8 with sodium polyoxyethylene lauryl ether acetate, and $\mathrm{pH} 4$ with disodium polyoxyethylene alkyl sulfosuccinate.

Table 4 shows the amount of surfactant remaining on the resin particles after washing two times and the HLB of the anionic surfactants. As shown in Table 4, little surfac$\operatorname{tant}(0.02 \mathrm{wt} \%$ to resins) remained when we used disodium polyoxyethylene alkyl sulfosuccinate because of the high HLB and little usage of the surfactant for emulsification. Conversely, considerable amount of surfactant $(0.62$ wt $\%$ to resins) remained when we used sodium polyoxyethylene lauryl ether acetate because of the low HLB and large usage of the surfactant for emulsification.

In addition, we investigated the impact of the number of washing times on the amount of surfactant remaining on resin particles. As shown in Fig. 3, when using disodium polyoxyethylene alkyl sulfosuccinate, the amount of surfactant remaining decreased to $0.02 \mathrm{wt} \%$ to resins upon washing two times, and even if the washing process was repeated, there was no significant difference. In the case of sodium polyoxyethylene lauryl ether sulfate and sodium polyoxyethylene lauryl ether acetate as surfactants, the amount of surfactant remaining gradually decreased when washing was repeated up to five times. Thus, we concluded that disodium polyoxyethylene alkyl sulfosuccinate not

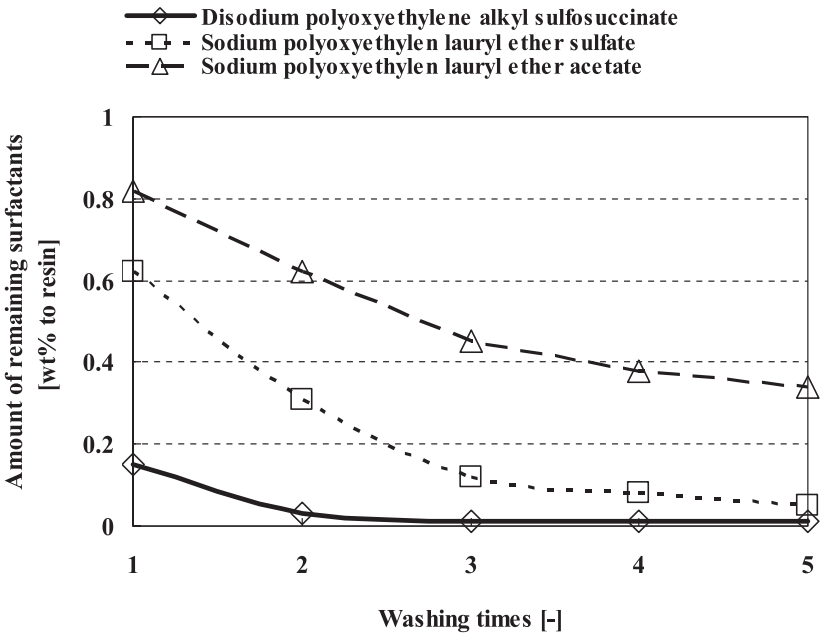

Fig. 3 Amount of remaining surfactant after every washing process.

only obtained clean particles with little amount of remaining surfactant but also dramatically reduced the amount of wastewater from the washing process.

\section{CONCLUSION}

This study investigated the application of the practical $\mathrm{pH}$ responsiveness of monoalkyl sulfosuccinate having two types of hydrophilic groups in one molecule to the dispersion granulation method. We successfully reduced the amount of surfactant necessary for emulsification as well as the amount of surfactant remaining on resin particles under the washing process by optimizing the HLB of the 
solution controlled by $\mathrm{pH}$ for each process.

We expect that clean surface resin particles based on this process could be used as high-performance resin particles such as carriers for medical testing in biological fields and spacer particles in the electronic industry material field.

\section{References}

1) Fujimoto, T. Introduction to Surfactants, Sanyo Chemical Industries LTD., Japan, pp. 90-107 (2007).

2) Interface and Surfactants, Japan Oil Chemist' Society, Japan, pp. 34-39 (2005).

3) Chemical Handbook, The Chemical Society of Japan, Chapter 10(1993).

4) Long, T. A.; Nutting, G. C.; Harkins, W. D. The Surface Tension of Aqueous Soap Solutions as a Function of Hydrogen Ion $(\mathrm{pH})$ and Salt Concentration . I. Sodium Laurate and Sodium Nonylate. J. Am. Chem. Soc. 59, 2197-2203(1937).

5) Andersen, D. L. Ampholytic Surface-Active Agents. J. Am. Chem. Soc. 34, 188-191 (1957).

6) Derjaguin, B. V.; Landau, L. Theory of the stability of strongly charged lyophobic sols and of adhesion of strongly charged particles in solution of electrolytes. Acta Physicochimica U. R. S. S., 14, 633-662(1941).
7) Verwey, E. J.; Overbeek, T. Th. G. Theory of the Stability of Lyophobic Colloids, Elsevier B. V., Part III (1948).

8) Applied Surface and Colloid Chemistry, John Willey \& Sons Ltd., Vol.1 289 (2002).

9) Sanyo Chemical Products Outline, Sanyo Chemical Industries LTD., No.2(2013).

10) New Developments in Resin Particle, Toray Research Center LTD., Chapter 1(1995).

11) Satta, K.; Iida, Y. Jap. Pat. Pub., S63-25664 (1986).

12) Onodera, S.; Kobayashi, J.; Ishizaki, K. Jap. Pat. Pub., H04-275339 (1992).

13) Hirayama, C.; Ihara, H. Jap. Pat. Pub., H04-246434 (1992).

14) Noda, H.; Takigawa, T. The Development of Production Method for Polyester Resin Particle Having Sharp Particle Size Distribution. KINKA, The Kinki Chemical Society Japan, 64, 14(2012).

15) Xu, Q.; Nakajima, M. The Emulsification Properties of Hydrophilic Silica Nanoparticles. Fragrance J. Specail Issue, 19, 39-44(2005).

16) Nonomura, Y. Solid-Stabilized Emulsions. Hyomen 42, 12-19 (2004).

17) Oda, R.; Teramura, K. Synthesis and Application of Surface Active Agents, Maki Book Publishers, pp. 501 (1957). 